\title{
Haemodynamic changes in ipsilateral and contralateral fingers caused by acute exposures to hand transmitted vibration
}

\author{
Massimo Bovenzi, Michael J Griffin
}

\begin{abstract}
Objectives-To investigate changes in digital circulation during and after exposure to hand transmitted vibration. By studying two frequencies and two magnitudes of vibration, to investigate the extent to which haemodynamic changes depend on the vibration frequency, the vibration acceleration, and the vibration velocity.

Methods-Finger skin temperature (FST), finger blood flow (FBF), and finger systolic pressure were measured in the fingers of both hands in eight healthy men. Indices of digital vasomotor tonesuch as critical closing pressure and vascular resistance-were estimated by pressure-flow curves obtained with different hand heights. With a static load of 10 $\mathbf{N}$, the right hand was exposed for $30 \mathrm{~min}$ utes to each of the following root mean squared (rms) acceleration magnitudes and frequencies of vertical vibration: 22 $\mathrm{m} . \mathrm{s}^{-2}$ at $31.5 \mathrm{~Hz}, 22 \mathrm{~m} . \mathrm{s}^{-2}$ at $125 \mathrm{~Hz}$, and 87 m.s $\mathrm{s}^{-2}$ at $125 \mathrm{~Hz}$. A control condition consisted of exposure to the static load only. The measures of digital circulation and vasomotor tone were taken before exposure to the vibration and the static load, and at $0,20,40$, and 60 minutes after the end of each exposure.
\end{abstract}

Results-Exposure to static load caused no significant changes in FST, FBF, or indices of vasomotor tone in either the vibrated right middle finger or the nonvibrated left middle finger. In both fingers, exposure to vibration of $125 \mathrm{~Hz}$ and $22 \mathrm{~m} \cdot \mathrm{s}^{-2}$ produced a greater reduction in FBF and a greater increase in vasomotor tone than did vibration of $31.5 \mathrm{~Hz}$ and 22 $\mathrm{m} . \mathrm{s}^{-2}$. In the vibrated right finger, exposure to vibration of $125 \mathrm{~Hz}$ and $87 \mathrm{~m} . \mathrm{s}^{-2}$ provoked an immediate vasodilation which was followed by vasoconstriction during recovery. The non-vibrated left finger showed a significant increase in vasomotor tone throughout the 60 minute period after the end of vibration exposure. Conclusions-The digital circulatory response to acute vibration depends upon the magnitude and frequency of the vibration stimulus. Vasomotor mechanisms, mediated both centrally and locally, are involved in the reaction of digital vessels to acute vibration. The pattern of the haemodynamic changes in the fingers exposed to the vibration frequencies used in this study do not seem to support the frequency weighting assumed in the current international standard ISO 5349.

\section{(Occup Environ Med 1997;54:566-576)}

Keywords: digital vasomotor tone; vibration frequency; vibration magnitude

Workers who use hand held vibrating tools can experience finger blanching attacks due to episodic vasospasm in the digital vessels. The whiteness of the digits represents the visible sign of an abrupt interruption of blood flow through the fingers. Such a phenomenon was first described by Raynaud in 1862 in a group of patients with peripheral vascular disorders of various origins. In occupational medicine, Raynaud's phenomenon caused by excessive exposure to hand transmitted vibration is also called vibration induced white finger (VWF) and is a prescribed disease in many countries.

It is thought that the conditions of exposure to vibration at the workplace play a prominent part in the development of VWF. Exposure variables, such as years of regular daily use of vibrating tools and the magnitude and frequency of vibration, represent the main predictors upon which the risk of VWF is assessed in the current standards for hand transmitted vibration. ${ }^{12}$ The findings of experimental investigations in both normal people and patients with VWF seem to suggest that the degree of vibration induced vasoconstriction in the digital vessels may depend on the frequency and magnitude of the vibratory stimulus..$^{3-6}$ Most reports indicate that the maximal reduction in finger blood flow (FBF) occurs during or after exposure to vibration in the range $80-125 \mathrm{~Hz}^{4-8} \mathrm{~A}$ limited number of investigations have also reported a significant decrease in FBF and finger skin temperature (FST) with vibration of $30-60 \mathrm{~Hz}$ and $250-500 \mathrm{~Hz}^{39}$ The results of some experiments show that unilateral vibration can provoke digital vasoconstriction not only in the exposed fingers but also in the contralateral non-vibrated fingers, and even in the toes. ${ }^{10-12}$ This seems to support the theory that vibration can induce a vasoconstrictor response through a central sympathetic reflex mechanism. ${ }^{13}{ }^{14}$

In a previous paper we reported that acute vibration with a frequency of $125 \mathrm{~Hz}$ and a root mean square (rms) acceleration of $87.5 \mathrm{~m} . \mathrm{s}^{-2}$ provoked an immediate vasodilation in the exposed finger of healthy men followed by a 
vasoconstriction which could be recorded in both the ipsilateral and the contralateral finger. ${ }^{15}$ It was hypothesised that both local and central pathophysiological mechanisms might be involved in the vascular response of a vibrated finger. The aim of the present study was to extend the previous investigation by exploring the effect of different combinations of magnitudes and frequencies of vibration on FBF, finger systolic pressure (FSP), and FST in normal subjects. The relation between blood flow and pressure was studied in both vibrated and non-vibrated fingers. The pressure-flow curves were used to obtain additional information on the haemodynamic changes induced by vibration, in particular whether a vibration stimulus applied to the finger can alter the zero flow pressure, or critical closing pressure, of the digital vessels. Pressure at zero flow has been defined as the transmural pressure at which blood flow ceases in small vessels with active wall tension produced by smooth muscle contraction. ${ }^{16}$ Positive pressures at zero flow have been shown in canine systemic arterial circulation, frogs' legs, rabbits' ears and hindlegs, dogs' femoral and coronary circulation, and human forearms and fingers. ${ }^{17-24}$ As there is experimental evidence that zero flow pressure is increased by vasoactive substances and interventions which enhance the activity of the sympathetic nervous system, in this study the critical closing pressure of the digital vessels has been used as an index of vasomotor tone. ${ }^{16} 1924$

A further aim of this study was to investigate the relation between the effects of acute vibration on digital circulatory function and the risk of chronic vascular injury from occupational exposure to hand transmitted vibration as assessed in an annex to the current international standard ISO 5349.'

\section{Methods}

SUBJECTS

Eight healthy men, aged 23 to 44 (mean 28.8) years, were enrolled in the study. Five men were white and natives of England, and the other three were natives of oriental countries. The subjects were students or researchers of the University of Southampton. They were neither affected with finger symptoms nor using medicines at the time of the investigation. None was a professional user of vibrating tools. The subjects read a list of medical contraindications and gave written informed consent to the study. The experiments were conducted according to the safety recommendations included in the British standard $7085 . .^{25}$ Each man was requested not to drink coffee or alcohol for at least two hours before the tests. There was only one smoker, who refrained from smoking for the same period before testing. The dimensions of the middle fingers of both hands of each subject were measured with vernier callipers to an accuracy of $0.5 \mathrm{~mm}$. The volumes and surface areas of the fingers were then calculated according to the method suggested by Garrett. ${ }^{26}$
HAEMODYNAMIC MEASUREMENTS IN THE FINGER Finger systolic pressure was measured by strain gauge plethysmography according to the technique proposed by Nielsen et al. ${ }^{27}$ A PVC plastic cuff $(2.5 \times 9 \mathrm{~cm})$ was fixed around the proximal phalanx of the middle finger of both hands and secured by a Velcro strip. The soft plastic tubes of the digital cuffs were connected to the pneumatic system of the plethysmograph (Digitmatic DM2000, Medimatic A/S, Copenhagen). Silastic strain gauges containing mercury were positioned at the base of the finger nails. The fingers were squeezed to cause venous outflow before the plastic cuffs were inflated to suprasystolic values. The pressure in the digital cuffs was then automatically deflated at a deflation rate of about $2 \mathrm{~mm} \mathrm{Hg} \cdot \mathrm{s}^{-1}$. The FSP was defined as the cuff pressure $(\mathrm{mm}$ $\mathrm{Hg}$ ) at which the first increase in fingertip volume was recorded.

Systolic and diastolic pressures in the upper arm (mm Hg) were measured at the beginning of each experimental session by an auscultatory technique with a standard cuff $(12 \times 33 \mathrm{~cm})$.

Finger blood flow was measured in the same fingers in which FSP was taken. The measures of FBF were obtained by a venous occlusion technique. The proximal phalangeal cuffs were suddenly inflated to a pressure of $60 \mathrm{~mm} \mathrm{Hg}$ with the increase in finger volume simultaneously registered by the strain gauges placed on the distal phalanges of the middle finger of both hands. A calibration signal corresponding to a voltage change of $1 \%$-that is, $1 \mathrm{ml}$ blood per $100 \mathrm{ml}$ tissue per minute-was marked on the printer paper before the inflation of the cuffs. The FBF was measured from the plethysmographic tracings according to the criteria of Greenfield et al. ${ }^{28}$ Measurements of FBF were expressed as $\mathrm{ml} .100 \mathrm{ml}^{-1} \cdot \mathrm{min}^{-1}$. Three to five plethysmographic recordings of FBF were taken for each condition and the mean value calculated.

Finger skin temperature $\left({ }^{\circ} \mathrm{C}\right)$ was measured by thermocouples attached by adhesive tape to the dorsal surfaces of the intermediate phalanges of the same fingers in which FBF and FSP were recorded. The thermocouples were connected to signal conditioning and to a personal computer running data acquisition and analysis software so as to measure the temperature to an accuracy of $0.5^{\circ} \mathrm{C}$. The room temperature was measured by a free thermocouple connected to the same system.

\section{EXPERIMENTAL DESIGN}

The investigation was performed in a laboratory with mean (SD) air temperature of 24.7 $(0.4)^{\circ} \mathrm{C}$. Subjects wore light clothing and sat in an upright position on an adjustable chair. Initially the hands were placed on a pivoted platform just above the level of the heart. After 20 minutes of acclimatisation, FBF and FSP were measured in the middle fingers of both hands. To reduce digital perfusion pressure, the digits were then raised to $12,24,36$, and $48 \mathrm{~cm}$ above the heart and both vascular measurements were repeated at each height. The measures of FSP and FBF at each finger height were used to establish a pressure-flow relation in the 
fingers. After obtaining baseline measurements, the subjects were asked to place their right (exposed) hand facing downward on a wooden surface $(100 \mathrm{~mm} \times 100 \mathrm{~mm})$ secured to the table of a Derritron VP4 electrodynamic vibrator. Visual feedback through an analogue meter allowed a constant downward force of 10 $\mathrm{N}$ to be maintained by the right hands of the subjects. The left (non-exposed) hands were positioned palm downward on the platform just above the level of the heart. The arrangement for generation of vibration and control of contact force has been described in more detail in a previous paper. ${ }^{15}$ All five fingers of the right hand were exposed to vibration in the vertical direction for 30 minutes. Three combinations of frequency and magnitude of unweighted rms acceleration were presented on different days: $22 \mathrm{~m} . \mathrm{s}^{-2}$ at $31.5 \mathrm{~Hz}, 22 \mathrm{~m} . \mathrm{s}^{-2}$ at $125 \mathrm{~Hz}$, and 87 $\mathrm{m} . \mathrm{s}^{-2}$ at $125 \mathrm{~Hz}$. The selection of the two acceleration magnitudes at $125 \mathrm{~Hz}$ was such that the lower had the same acceleration as the $31.5 \mathrm{~Hz}$ acceleration whereas the higher had the same velocity as the $31.5 \mathrm{~Hz}$ velocity $\left(0.11 \mathrm{~m} . \mathrm{s}^{-1}\right.$ rms). Moreover, the $31.5 \mathrm{~Hz}, 22 \mathrm{~m} . \mathrm{s}^{-2}$ and the $125 \mathrm{~Hz}, 87 \mathrm{~m} . \mathrm{s}^{-2}$ vibration had the same frequency weighted acceleration $\left(11 \mathrm{~m} \cdot \mathrm{s}^{-2} \mathrm{rms}\right)$ according to international standard ISO 5349 and British standard BS 6842, and the $125 \mathrm{~Hz}$, $22 \mathrm{~m} . \mathrm{s}^{-2} \mathrm{rms}$ stimulus had a frequency weighted acceleration of $2.8 \mathrm{~m} . \mathrm{s}^{-2} \mathrm{rms}^{1{ }^{2}}$

The FBF and FSP were measured immediately after the end of vibration and at 20,40, and 60 minutes after the end of each vibration exposure. On each occasion, vascular measurements were taken with the hands just above the heart level and again at four heights as described for the pre-exposure condition. Blood flow in the non-exposed left finger was also recorded at 0 (within $30 \mathrm{~s}$ ), 10,20, and 30 minutes during exposure of the right hand to vibration. The measurement of FBF in the right hand during exposure to vibration was not practicable because contact of the strain gauge with the vibrating surface disturbed the plethysmographic recordings.

Finger skin temperature and room temperature were measured throughout the investigation with recordings taken before exposure to vibration, every 10 minutes during exposure, and every 20 minutes during recovery.

A control condition involved the same procedure, with the vibration magnitude reduced to zero but the contact force on the wooden surface maintained at $10 \mathrm{~N}$. The exposure (vibration) and control (static load) conditions were presented randomly (according to a latin square) in four separate experimental sessions. Each measurement session lasted about 2.5 hours.

\section{STATISTICAL METHODS}

Data analysis was conducted with the software BMDP/Dynamic (release 7.0). Data are given as means (SEM). The difference between two means was tested by paired or unpaired Student $t$ tests when appropriate. The relation between blood flow and pressure in the finger at different hand heights was assessed by the method of least squares. The Pearson product moment correlation coefficient was used to measure the strength of association between two variables. As vascular measurements were made sequentially upon the same subjects in different exposure conditions (treatments), analysis of variance (ANOVA) for repeated measures was applied to these data. To control for the effect of covariates on the response variables, repeated measures analysis of covariance (ANCOVA) was also used. When the assumption of compound symmetry for the orthogonal polynomial components of repeated measures was in doubt, an adjusted $F$ test was obtained according to the method proposed by Greenhouse and Geisser. ${ }^{29}$ A P value of 0.05 (two sided) was chosen as the limit of significance.

\section{Results}

Preliminary data analysis showed that there were no significant differences across the four experimental sessions for room temperature (range $24.2-25.8^{\circ} \mathrm{C}$ ) or systolic and diastolic blood pressures measured in the upper arms of the subjects (range 100/60-120/80 $\mathrm{mm} \mathrm{Hg}$ ). Repeated measures ANOVA did not show a significant difference within subjects for FST, FBF, or FSP measured just above heart level before exposures to static load and vibration in either the exposed or the non-exposed finger. Moreover, before exposure, no difference in FST, FBF, and FSP was found between the middle right and the middle left finger. In preexposure conditions, there were significant correlations between FST and FBF $(\mathrm{P}<0.01)$ and between FBF and FSP $(P<0.001)$ in both fingers. No significant association was found between FST and FSP. Age and finger volume were marginally related to FSP $(P=0.06)$ and FBF $(P=0.08)$, respectively. Owing to the well controlled environmental conditions, room temperature was not significantly correlated with FST, FBF, or FSP. The repeatibility of the measures of digital circulation across different testing sessions has been reported elsewhere. ${ }^{15}$

\section{FINGER SKIN TEMPERATURE}

Table 1 reports the mean (SEM) values of FST before and after exposure to static load and vibration. When controlling for age, finger surface area, and room temperature, no significant treatment by time interaction was found by repeated measures ANCOVA. There were no significant differences between the four exposure conditions. However, the percentage changes in FST after vibration were slightly greater that those after exposure to static load only. In the non-exposed left finger, no significant variations in FST, compared with before exposure, occurred during vibration stimulation of the right hand (results not shown).

\section{FINGER BLOOD FLOW}

Table 2 shows the effect of the exposure to static load and vibration on FBF. As repeated measures ANCOVA showed a significant treatment by time interaction $(P<0.001)$, the changes of FBF under the different exposure conditions were examined separately. Exposure to static load only did not cause significant changes in FBF. Vibration with a frequency of 
Table 1 Mean (SEM) values for finger skin temperature $\left({ }^{\circ} \mathrm{C}\right.$ ) measured in eight healthy men before and after 30 minute exposures to static load (contact force $10 \mathrm{~N}$ ) and vibration with three different combinations of frequencies (Hz) and magnitudes of acceleration (m.s ${ }^{-2} \mathrm{rms}$ )

\begin{tabular}{|c|c|c|c|c|c|}
\hline \multirow[b]{2}{*}{ Test } & \multirow[b]{2}{*}{ Values before exposure } & \multicolumn{4}{|l|}{ Recovery (min) } \\
\hline & & 0 & 20 & 40 & 60 \\
\hline \multicolumn{6}{|l|}{ Static load: } \\
\hline Exposed finger & $33.9(0.6)[100]$ & $35.2(0.2)[104]$ & $34.6(0.5)[102]$ & $34.0(0.5)[100]$ & $33.2(0.5)[98.0]$ \\
\hline Non-exposed finger & $34.2(0.6)[100]$ & $35.2(0.3)[100]$ & $34.8(0.5)[101]$ & $34.2(0.6)[100]$ & $33.1(0.7)[97.0]$ \\
\hline \multicolumn{6}{|c|}{ Vibration $31.5 \mathrm{~Hz}, 22 \mathrm{~m} \cdot \mathrm{s}^{-2}$ : } \\
\hline Exposed finger & $34.3(0.5)[100]$ & $35.3(0.3)[103]$ & $34.3(0.5)[99.8]$ & $33.5(0.6)[97.5]$ & $33.4(0.7)[97.2]$ \\
\hline Non-exposed finger & $34.3(0.5)[100]$ & $35.0(0.5)[102]$ & $34.3(0.7)[99.9]$ & $33.5(0.8)[97.6]$ & $33.0(0.8)[96.3]$ \\
\hline \multicolumn{6}{|c|}{ Vibration $125 \mathrm{~Hz}, 22 \mathrm{~m} \cdot \mathrm{s}^{-2}$ : } \\
\hline Exposed finger & $33.8(0.5)[100]$ & $35.2(0.2)[104]$ & $34.0(0.5)[101]$ & $33.1(0.6)[98.3]$ & $32.1(0.7)[95.4]$ \\
\hline Non-exposed finger & $34.1(0.4)[100]$ & $34.9(0.3)[103]$ & $33.8(0.5)[99.3]$ & $32.8(0.5)[96.5]$ & $31.9(0.6)[94.0]$ \\
\hline \multicolumn{6}{|c|}{ Vibration $125 \mathrm{~Hz}, 87 \mathrm{~m} . \mathrm{s}^{-2}$ : } \\
\hline Exposed finger & $33.9(0.4)[100]$ & $35.0(0.3)[104]$ & $34.2(0.4)[101]$ & $33.6(0.5)[99.2]$ & $32.8(0.5)[96.8]$ \\
\hline Non-exposed finger & $34.3(0.5)[100]$ & $34.0(0.4)[99.2]$ & $33.3(0.6)[97.1]$ & $32.7(0.5)[96.6]$ & $32.1(0.6)[93.7]$ \\
\hline
\end{tabular}

Percentage of values before exposure are in square brackets.

Table 2 Mean (SEM) values for finger blood flow ( $\left.\mathrm{ml} .100 \mathrm{ml}^{-1} . \mathrm{min}^{-1}\right)$ measured in eight healthy men before and after 30 minute exposures to static load (contact force $10 \mathrm{~N}$ ) and vibration with three different combinations of frequencies $(\mathrm{Hz})$ and magnitudes of acceleration (m. ${ }^{-2}$ rms)

\begin{tabular}{|c|c|c|c|c|c|}
\hline \multirow[b]{2}{*}{ Test } & \multirow[b]{2}{*}{ Values before exposure } & \multicolumn{4}{|l|}{ Recovery (min) } \\
\hline & & 0 & 20 & 40 & 60 \\
\hline \multicolumn{6}{|l|}{ Static load: } \\
\hline Exposed finger & $27.6(4.7)[100]$ & $27.9(4.6)[103]$ & $26.0(5.2)[95.0]$ & $25.3(4.9)[91.4]$ & $26.9(5.3)[98.4]$ \\
\hline Non-exposed finger & $33.4(6.5)[100]$ & $33.8(7.6)[97.6]$ & $32.8(6.0)[102]$ & $31.2(6.5)[95.7]$ & $32.2(6.5)[98.3]$ \\
\hline \multicolumn{6}{|c|}{ Vibration $31.5 \mathrm{~Hz}, 22 \mathrm{~m} . \mathrm{s}^{-2}$ : } \\
\hline Exposed finger $\neq$ & $29.5(5.2)[100]$ & 22.9 (4.8) [91.6] & $18.7(3.7)[64.9]$ & $17.2(4.4)[56.9]$ & $12.5(4.0)[42.4]$ \\
\hline Non-exposed finger $\neq$ & $36.2(4.9)[100]$ & $28.9(5.3)[82.9]$ & $22.4(4.4)[60.2]$ & $19.2(3.8)[52.3]$ & $15.8(4.5)[41.5]$ \\
\hline Exposed finger $\ddagger$ & $35.0(5.3)[100]$ & $23.3(3.3)[74.9]$ & $18.6(4.3)[54.8]$ & $14.9(4.0)[45.1]$ & $11.3(3.4)[34.3]$ \\
\hline Non-exposed finger $\ddagger$ & $44.3(5.3)[100]$ & $28.4(3.1)[69.7]$ & $22.8(5.5)[50.1]$ & $14.9(3.6)[34.6]$ & $13.1(3.8)[30.3]$ \\
\hline \multicolumn{6}{|c|}{ Vibration $125 \mathrm{~Hz}, 87 \mathrm{~m} \cdot \mathrm{s}^{-2}$ : } \\
\hline Exposed fingert & $24.5(3.9)[100]$ & $33.4(6.2)[145]^{\star}$ & $15.8(2.9)[72.7]$ & $15.1(3.1)[65.5]$ & $10.9(2.7)[50.9]$ \\
\hline Non-exposed finger & $29.0(4.1)[100]$ & $23.7(4.7)[78.4]$ & $15.1(2.6)[55.6]$ & $14.8(3.0)[54.2]$ & $11.8(3.0)[42.2]$ \\
\hline
\end{tabular}

$\star \mathrm{P}<0.01$, Student $t$ test (exposed $v$ non-exposed finger). $\dagger \mathrm{P}<0.01, \ddagger \mathrm{P}<0.001$, repeated measures analysis of covariance (P values adjusted by age, finger volume, and room temperature). Percentage of values before exposure are in square brackets.

either $31.5 \mathrm{~Hz}$ or $125 \mathrm{~Hz}$ with an acceleration of $22 \mathrm{~m} . \mathrm{s}^{-2}$ provoked a significant reduction in FBF in both the vibrated and the non-vibrated finger. Compared with pre-exposure measures, the percentage decrease in FBF at each recovery time was greater after exposure to $125 \mathrm{~Hz}$ at $22 \mathrm{~m} . \mathrm{s}^{-2}$ than after exposure to $31.5 \mathrm{~Hz}$ at 22 $\mathrm{m} . \mathrm{s}^{-2}(\mathrm{P}<0.05)$. Exposure to vibration acceleration of $87 \mathrm{~m} . \mathrm{s}^{-2}$ at $125 \mathrm{~Hz}$ caused a significant increase in FBF in the vibrated finger immediately after the end of the exposure. Such a vasodilation was not found in the non-vibrated finger and the difference in the mean FBF between the two fingers was highly significant $(P<0.01)$. The vasodilation in the vibrated finger was followed by a decrease in FBF which was significant for the FBF measured both before and immediately after the vibration exposure $(P<0.01)$. A significant reduction in FBF during recovery was also found in the non-vibrated finger. In either finger, the percentage change in FBF at 20,40, and 60 minutes after exposure to each of the vibration conditions was significantly lower than that after static load only $(0.001<\mathrm{P}<0.03)$. No difference in FBF was found between the various vibration stimuli during recovery, except for FBF recorded in the vibrated finger immediately after the end of vibration exposure owing to the vasodilation which occurred in that finger after vibration of $125 \mathrm{~Hz}$ at $87 \mathrm{~m} . \mathrm{s}^{-2}$ $(P<0.05)$. Table 3 reports the mean values of FBF measured in the non-exposed left finger during the 30 minute exposures of the right hand to static load only or to vibration and static load. There was no significant difference across the four testing sessions for the preexposure measures of FBF $(P=0.23)$. The treatment by time interaction was marginally not significant $(\mathrm{P}=0.08)$. There was a significant difference between the four testing conditions even when either the pre-exposure measures of FBF or FBF at the beginning of the different exposures were excluded from data analysis $(P<0.05)$. When the pre-exposure measures of FBF were included as a covariate in the repeated measures ANOVA, the treatment by time interaction term was not significant $(P=0.89)$ and the difference between the four testing sessions remained highly significant $(\mathrm{P}<0.02)$.

FINGER SYSTOLIC PRESSURE

Exposure to static load only, or to vibration and static load, caused no significant changes in FSP during the recovery when compared with the baseline measures in either the exposed or the non-exposed finger (results not shown).

\section{PRESSURE-FLOW RELATION}

The pairs of blood flow measures and pressure measures in each finger at the different hand heights before exposure, and at each recovery time after exposure to static load or vibration, were plotted to establish pressure-flow relations. In agreement with the methods used by other researchers, ${ }^{18-20}{ }^{24}$ the zero flow intercept on the pressure axis (critical closing pressure) was estimated by linear extrapolation of the fitted regression line (fig 1). Resistance of the 
Table 3 Mean (SEM) values for finger blood flow measured in the non-exposed finger of eight healthy men before and during 30 minute exposures to static load (contact force $10 \mathrm{~N}$ ) and vibration with three different combinations of frequencies $(\mathrm{Hz})$ and magnitudes of acceleration (m.s $\mathrm{s}^{-2} \mathrm{rms}$ )

\begin{tabular}{lllll}
\hline \multicolumn{5}{c}{ Vibration } \\
\cline { 3 - 5 } Period & Static load & $31.5 \mathrm{~Hz} 22 \mathrm{m.s}^{-2}$ & $125 \mathrm{~Hz} 22 \mathrm{m.s}^{-2}$ & $125 \mathrm{~Hz} 87 \mathrm{m.s}^{-2}$ \\
\hline $\begin{array}{l}\text { Before } \\
\quad \text { exposure }\end{array}$ & $33.4(6.5)[100]$ & $36.2(4.9)[100]$ & $44.4(5.3)[100]$ & $29.0(4.1)[100]$ \\
$\begin{array}{l}\text { Exposure (min): } \\
0\end{array}$ & $37.7(6.6)[116]$ & $34.8(6.9)[91.1]$ & $34.9(6.4)[76.3]$ & $29.8(5.8)[103]$ \\
10 & $35.6(6.2)[108]$ & $32.8(5.9)[88.3]$ & $32.3(6.2)[70.4]$ & $24.4(6.6)[80.5]$ \\
20 & $32.4(6.8)[94.7]$ & $33.4(6.3)[86.1]$ & $30.3(4.5)[69.8]$ & $25.6(4.3)[87.4]$ \\
30 & $34.0(6.6)[103]$ & $32.5(7.3)[82.3]$ & $28.4(5.5)[62.8]$ & $25.9(5.1)[86.0]$ \\
\hline
\end{tabular}

Repeated measures analysis of covariance for the difference between testing conditions: $P<0.05$ (covariates: age, finger volume, and room temperature); $\mathrm{P}<0.02$ (covariates: age, finger volume, room temperature, and measures of FBF before exposure). Percentage of values before exposure are in square brackets.

digital vessels was estimated by the reciprocal of the slope of the pressure-flow relation-that is, the change in pressure for a unit change in flow (mm Hg.min. $100 \mathrm{ml} \cdot \mathrm{ml}^{-1}$ ). Tables 4 and 5 report the mean (SEM) values of the estimated zero flow pressure and vascular resistance in both the exposed and non-exposed fingers. Before exposure there was no difference in the estimates of either zero flow pressure or vascular resistance, either between the various testing sessions or between the middle right and the middle left finger within each session. The $F$ test for the treatment by time interaction term was found to be highly significant for both zero flow pressure and vascular resistance $(P<0.01)$. Therefore, the analysis of the results was performed within each exposure condition. Exposure to static load caused no changes

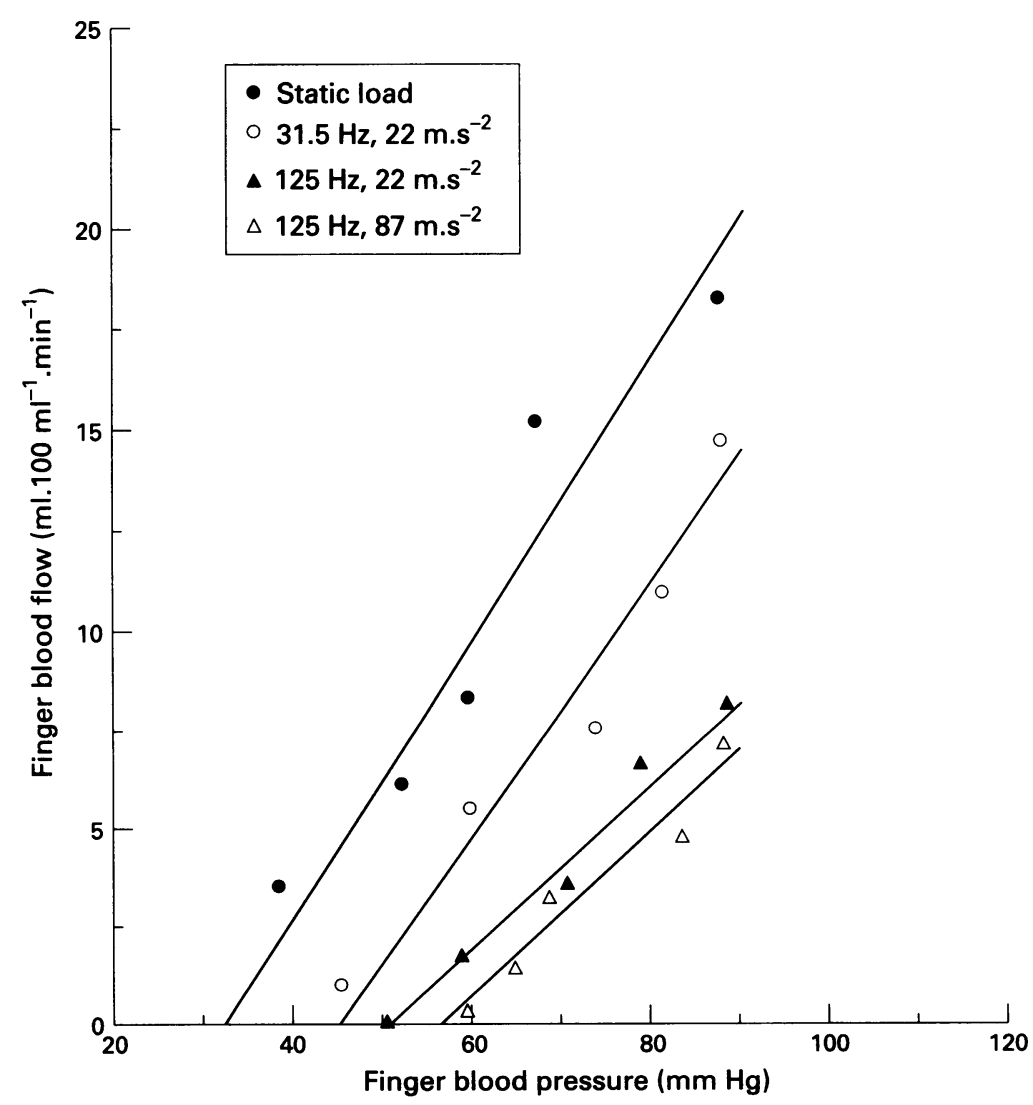

Figure 1 Digital pressure-flow relations in the exposed finger of a healthy subject at 60 minutes after the end of a 30 minute exposure to static load and vibration with three different combinations of frequencies $(\mathrm{Hz})$ and magnitudes of acceleration $\left(m \cdot \mathrm{s}^{-2} \mathrm{rms}\right)$. The pressure-flow relations were estimated at different hand heights at five levels above the heart. The zero flow pressure intercept $(\mathrm{mm} \mathrm{Hg})$ was obtained by linear extrapolation. in zero flow pressure or vascular resistance relative to the baseline estimates in either finger. Exposure to vibration at the different frequencies and acceleration magnitudes gave rise to a significant increase in both zero flow pressure and vascular resistance in both the vibrated and the non-vibrated finger $(P<0.01)$. The decrease of zero flow pressure and vascular resistance found in the vibrated finger immediately after the end of exposure to vibration of $125 \mathrm{~Hz}$ at $87 \mathrm{~m} \cdot \mathrm{s}^{-2}$ is consistent with the simultaneous increase in FBF measured in the same finger.

The estimates of the intercepts and the slopes of the pressure-flow relations after static load were significantly different from those after vibration and static load $(P<0.01)$, but no difference was found between the vibration stimuli during recovery with the exception of the pressure-flow curves obtained immediately after vibration ended $(P<0.05)$. In each subject the increase in finger vascular resistance after vibration exposure was related to either the decrease in FBF or the increase in zero flow pressure. The strongest correlations were found in the exposed finger after stimulation with the vibration at $125 \mathrm{~Hz}(0.001<\mathrm{P}<0.05)$. Figures 2 and 3 show the scattergrams of the estimates of vascular resistance versus FBF and zero flow pressure, respectively, by pooling the total set of measures obtained in the exposed finger before and after stimulation with vibration of $125 \mathrm{~Hz}$ at $22 \mathrm{~m} \cdot \mathrm{s}^{-2}$.

\section{Discussion}

In this study several conventional measures of circulatory function-such as FST, FBF, and FSP - were used to assess the effect of static load and vibration on the digital vessels of healthy subjects. Also, at each recording time, pressure-flow curves were obtained by lowering the digital perfusion and transmural pressures by raising the height of the hand. The estimated regression coefficients of the pressure-flow lines were used to characterise the haemodynamics of the digital vessels in terms of critical closing pressure (zero flow pressure intercept) and vascular resistance (reciprocal of the regression slope). In this study, the basal critical closing pressure in normal fingers at room temperature before exposure averaged $36 \mathrm{~mm} \mathrm{Hg}$ and ranged between 18 and $55 \mathrm{~mm} \mathrm{Hg}$. These findings are consistent with those reported by other authors who found that in thermoneutral conditions the closing pressure of the finger varies from 10 to $60 \mathrm{~mm} \mathrm{Hg}{ }^{22-24} \mathrm{On}$ the basis of the findings of previous investigations, it was assumed that vibration increases the vasomotor tone in the digital vessels. ${ }^{3513}$ In this study, pressure-flow curves after exposure to vibration showed greater zero flow pressure intercepts and lower slopes than after exposure to static load without vibration (fig 1 ). This suggests that vibration enhances digital vasomotor tone and that this leads to increases in both the critical closing pressure and the vascular resistance. Even though the closing pressure in the finger was found to vary directly with digital vascular resistance, this positive relation was not shown 
Table 4 Mean (SEM) values for pressure at zero flow ( $\mathrm{mm} \mathrm{Hg}$ ) in the digital vessels of eight healthy men before and after 30 minute exposure to static load (contact force $10 \mathrm{~N}$ ) and vibration with three different combinations of frequencies $(\mathrm{Hz})$ and magnitudes of acceleration (m.s ${ }^{-2}$ rms)

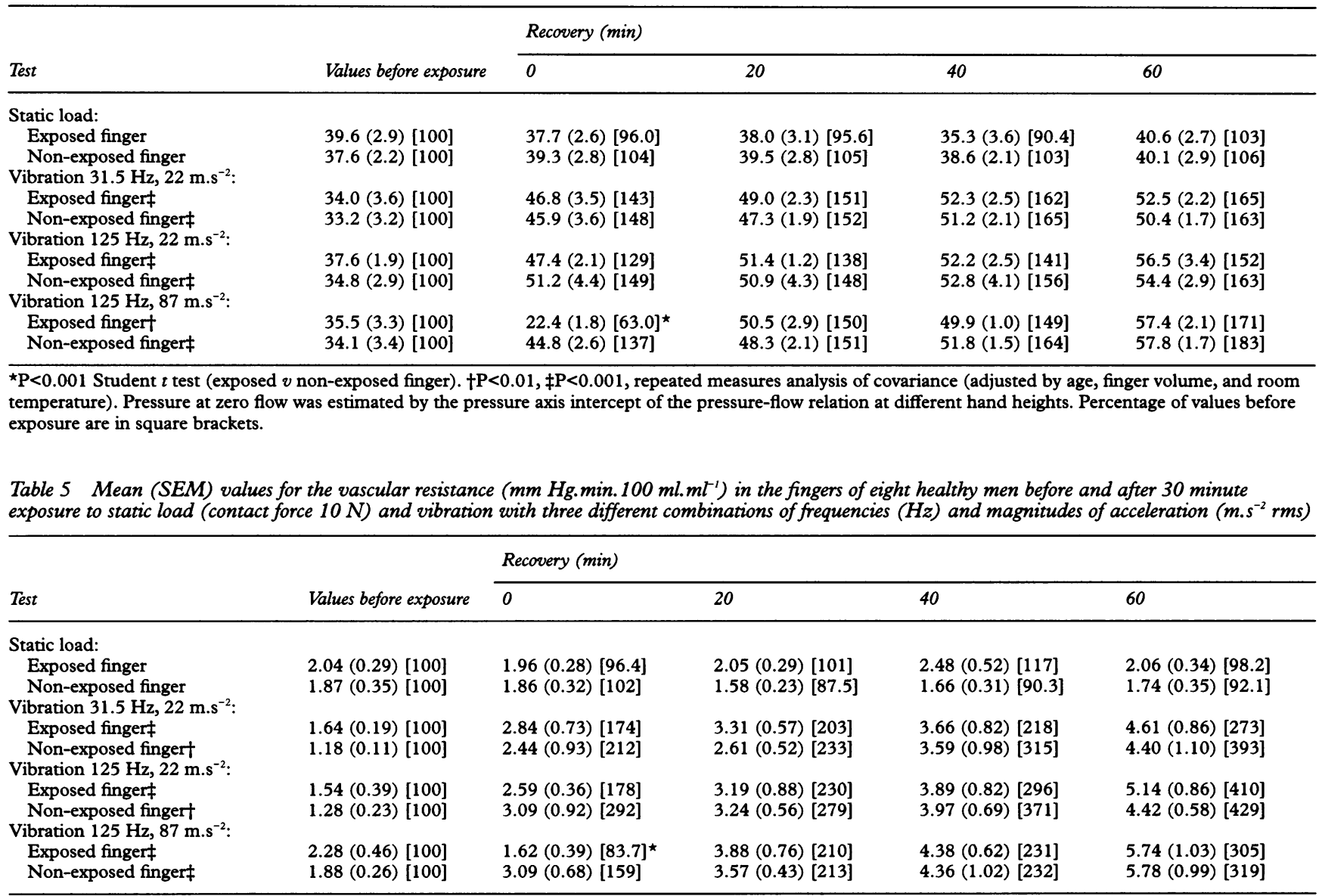

$\star \mathrm{P}<0.05$, Student $t$ test (exposed $v$ non-exposed finger). $\dagger \mathrm{P}<0.05, \neq \mathrm{P}<0.01$, repeated measures analysis of covariance (adjusted by age, finger volume, and room temperature). Vascular resistance was estimated by the reciprocal of the slope of the pressure-flow relation at different hand heights.

to be valid in other experimental studies of major circulations-for instance, in the cerebral vascular bed of monkeys and in the canine systemic arterial circulation during hypoxia. ${ }^{19} 30$ This may arise because vascular resistance is determined not only by the vessel calibre but also by other factors such as the size of the vascular bed and the fluid viscosity. ${ }^{18}$ As there is experimental evidence that changes in zero flow pressure reflect changes in vascular smooth muscle active tension, some investigators believe that critical closing pressure in small arteries and arterioles is a more reliable index of vasomotor tone than peripheral vascular resistance..$^{171830}$ However, the interpretation of a critical closing pressure in small blood vessels with active wall tension is still controversial among physiologists. According to Burton and co-workers, in the presence of active tone, the critical closing pressure is the level of arterial transmural pressure below which a sudden collapse of the vessels occurs owing to an unstable equilibrium between wall tension and transmural distending forces. ${ }^{16}{ }^{17} \mathrm{It}$ has also been suggested that the closing phenomenon could be produced by a distortion of the inner layers of the vessel wall during active contraction which causes bulging of the endothelium into the vascular lumen and ultimately the physical closure of the vessel. ${ }^{31} \mathrm{~A}$ different haemodynamic model has been proposed by Permutt and Riley and, more recently, by other investigators to account for a critical closing pressure in the resistance vessels. ${ }^{18-2032}$ They argued that the positive zero flow intercept of the pressure-flow relation represents the effective back pressure to arterial flow during perfusion. Assuming that the active tension developed by the muscular wall of the small arteries and arterioles causes a critical closing pressure, then blood flow stops when there is no pressure gradient between the inflow pressure and the closing pressure produced by the active wall tension. According to this model, an increase in vasomotor tone would increase the critical closing pressure, and consequently, the pressure gradient reduces and blood flow decreases.

The findings of the present study indicate that vibration can affect the digital circulatory function in both the exposed and the nonexposed fingers of healthy people. In contrast, exposure to static load without vibration did not provoke any significant changes in the digital circulation of either finger. The results of the haemodynamic measurements seem to suggest that the response of the digital vessels to vibration may depend on the frequency of the vibration stimulus. In the vibrated finger, 30 minute exposures to vibration with an acceleration of $22 \mathrm{~m} \cdot \mathrm{s}^{-2} \mathrm{rms}$ caused digital vasoconstriction at both 31.5 and $125 \mathrm{~Hz}$. Compared with before exposure, the decrease in FBF and the increase in vascular resistance were greater after vibration with a frequency of $125 \mathrm{~Hz}$ than after vibration with a frequency of 
31.5 Hz. Hence, for an exposure to the same magnitude of acceleration there is some evidence of a frequency dependency in the haemodynamic changes in a vibrated finger. This finding is in agreement with other experimental studies which reported that vibration of $125 \mathrm{~Hz}$ was the most effective in reducing FBF in healthy subjects and in inducing vasospastic reactions in the fingers of workers affected with VWF. $^{78}$

All of the three vibration stimuli used in this study were found to provoke digital vasoconstriction in the contralateral finger. It has been suggested that vibration can trigger a central sympathetic reflex which results in vasomotor effects in areas of the human body distant from the site of application of the vibratory stimulus. $^{3561011}$ Neurophysiological studies of skin mechanoreceptors by microneurographic techniques have shown that the sensitivities to vibration of the dermal Meissner corpuscles and the subcutaneous Pacinian corpuscles are greatest at the frequencies of $8-64 \mathrm{~Hz}$ and $128-400 \mathrm{~Hz}$, respectively. ${ }^{33}$ Our findings of a vasoconstrictor response in the non-vibrated finger after exposure to vibration at 31.5 and $125 \mathrm{~Hz}$ are not inconsistent with the hypothesis that these skin organs may represent the afferent receptor system of the sympathetic reflex arch elicited by vibration.

The circulatory response found in the vibrated finger immediately after the end of exposure to vibration with a frequency of 125 $\mathrm{Hz}$ and an acceleration of $87 \mathrm{~m} \cdot \mathrm{s}^{-2} \mathrm{rms}$ was characterised by local vasodilatation with an increase in FBF and a decrease in both critical closing pressure and vascular resistance. Such a vasodilation was not found in the non-vibrated finger. This pattern of response is consistent with that reported in our previous investigation in which normal fingers were also exposed to vibration of $125 \mathrm{~Hz}$ and $87.5 \mathrm{m.s}{ }^{-2} \mathrm{rms}^{15}$ Vibration induced relaxing effects on smooth muscle have been found in both isolated muscle preparations and whole experimental animals, as well as in human hands. Ljung and Sivertsson reported that vibration of $10-400$ $\mathrm{Hz}$ depressed the contractile force of smooth muscle in preparations of isolated rat portal veins and rabbit thoracic aortas. ${ }^{34}$ They suggested that vibration has a direct mechanical effect on the elements generating force by increasing the rate of detachment of actinmyosin cross links. The hypothesis of a direct inhibition of the contractile process by vibration was also proposed by Lindblad et al who found that the depression of contractions in rings of isolated canine saphenous arteries increased with both the amplitude (0.025- 0.10 mm peak) and the frequency $(30-150 \mathrm{~Hz})$ of vibration. ${ }^{35}$ Whole animal studies have shown that vibration increases blood flow in rabbit gastrocnemius and decreases peripheral resistance in dogs' forelegs and hindlegs. ${ }^{36-38}$ In these experiments, no notable change in arterial pressure was found, indicating that vibration caused a vasodilatation in the resistance vessels. A transitory vasodilatation in the human finger has been documented during and after short exposures (five minutes) to vibration with a frequency of 60,120 , and 480 $\mathrm{Hz}^{39}{ }^{40}$ In the present study the immediate vasodilatory response in the fingers exposed to vibration of $125 \mathrm{~Hz}$ and $87 \mathrm{~m} \cdot \mathrm{s}^{-2} \mathrm{rms}$ seems to have been dependent on the frequency and the magnitude of the stimulus. This is because a digital vasoconstriction was found immediately after exposure to vibration with a frequency of $31.5 \mathrm{~Hz}$ with the same velocity $\left(0.11 \mathrm{~m} . \mathrm{s}^{-1} \mathrm{rms}\right)$ and also after exposure to vibration with the same frequency but with a lower acceleration (22 m.s $\left.\mathrm{s}^{-2} \mathrm{rms}\right)$. In the aforementioned studies an inhibitory effect of vibration on the contractile activity of vascular smooth muscles was more evident for exposures to vibration with frequencies of $100-150 \mathrm{~Hz}$ and accelerations $>40-50 \mathrm{~m} \cdot \mathrm{s}^{-2} \mathrm{rms}$. Hence, it may be speculated that there exists a threshold acceleration magnitude above which acute vibration can depress the contraction of vascular smooth muscle cells either directly, by mechanical injury of the contractile proteins, or through the local release of vasodilating substancesfor example, endothelial derived relaxing factor, prostacyclin - caused by vibration induced enhancement of arterial wall shear stress. Neurophysiological investigations have shown that the number of impulses evoked from Pacinian corpuscles with a stimulus frequency of $128 \mathrm{~Hz}$ was similar in the range of acceleration between 14 and $229 \mathrm{~m} . \mathrm{s}^{-2} \mathrm{rms} .{ }^{33}$ Suppose that a central sympathetic reflex mediated by the Pacinian corpuscles leads to digital vasoconstriction after exposure to vibration with a frequency of $125 \mathrm{~Hz}$ at a low acceleration magnitude, whereas at higher acceleration magnitudes the vasoconstrictor effect induced by the unchanged response of the Pacinian receptors is overcome by the depressant effect of vibration on the vascular smooth muscles and that this results in active local vasodilation. The opposite and competitive effects of a central vasoconstrictor and a local vasodilatory mechanism, both elicited by acute vibration, could provide an explanation for the unchanged digital vascular response found in some studies in which either the duration of exposure or the magnitude of the vibratory stimulus were lower than those used in the present investigation. ${ }^{54}$

In an experimental study of vibration and arterial circulation in the hindlegs of anaesthetised dogs Azuma et al reported that three hour exposures to vibration of $60 \mathrm{~Hz}$ in frequency and about $30 \mathrm{~m} \cdot \mathrm{s}^{-2}$ in acceleration magnitude significantly affected the changes in peripheral vascular resistance induced by noradrenaline. ${ }^{38}$ The enhancement of vasomotor tone caused by noradrenaline was decreased during, and increased one hour after, the vibration stimulation. An exaggerated digital vasoconstrictor response to cold one hour after the end of 30 minute exposure to vibration of $31.5 \mathrm{~Hz}$ and 32 $\mathrm{m} . \mathrm{s}^{-2} \mathrm{rms}$ has also been found by Olsen in both the vibrated and non-vibrated fingers of healthy men. ${ }^{41}$ These results agree with the findings of the present study which showed that when compared with baseline the greatest rise in both closing pressure and vascular resistance in the vibrated and the non-vibrated finger occurred at 40-60 minutes after the end of 


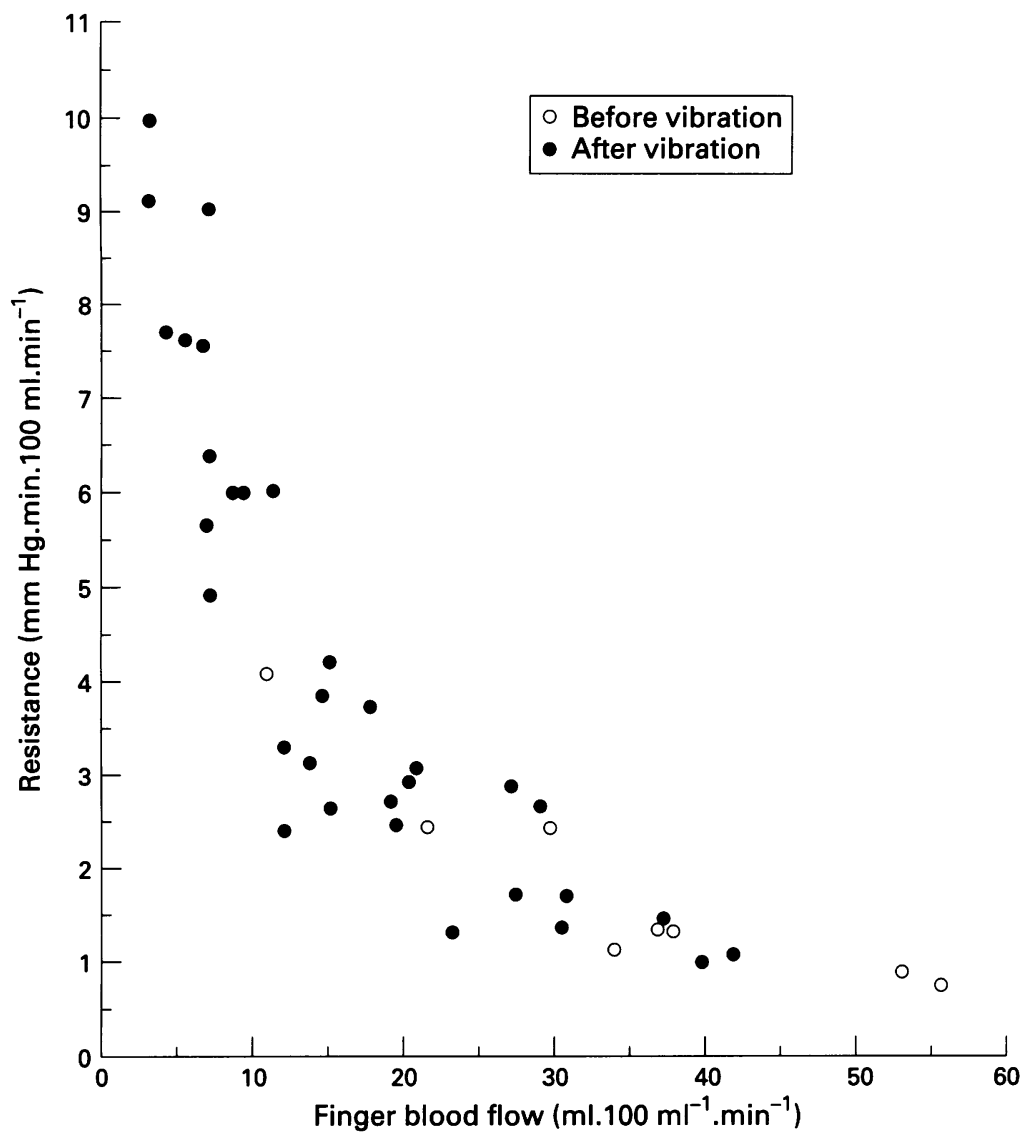

Figure 2 Scattergram of the estimates of vascular resistance $v$ finger blood flow in the exposed fingers of eight healthy subjects before and after 30 minute exposures to vibration of $125 \mathrm{~Hz}$ and $22 \mathrm{~m} . \mathrm{s}^{-2} \mathrm{rms}$. The vascular resistance was estimated by the reciprocal of the slope of the pressure-flow relation at different hand heights.

exposure to vibration of 31.5 and $125 \mathrm{~Hz}$. This suggests that acute vibration of low and middle frequency has persisting after effects on digital vasomotor tone which result in a progressive reduction of blood supply to the fingers. The bilateral occurrence of these prolonged after effects could be consistent with the view that the vasoconstrictor response to vibration is mediated through a central sympathetic reflex mechanism. ${ }^{5134142}$ It may alternatively be hypothesised that the long lasting constrictor effect of vibration is initially triggered by an increased sympathetic nervous activity and then maintained by the release of vasoactive substances such as endothelin-1 from the vascular endothelial and smooth muscle cells. ${ }^{43}$ Endothelin-1 (ET-1) is a vasoactive peptide with a potent and prolonged in vitro and in vivo vasoconstrictor activity. ${ }^{44}$ It is thought that endogenous production of ET-1 contributes to the maintenance of the basal vascular tone in humans. ${ }^{45}$ Intra-arterial infusion of endothelin-1 was found to cause progressive forearm vasoconstriction in healthy men, reaching a maximum at 55-90 minutes during infusion and then reversing slowly to basal flow values ( 120 minutes) after stopping the infusion. ${ }^{45} 46$ It has been predicted that vibration can induce arterial wall shear stress and that this may be related to the vascular disorders found in workers who use vibrating tools. ${ }^{47}$ In vitro studies have shown that shear stress can either increase or decrease the release of ET-1 from cultured endothelial cells, depending on the magnitude and duration of the shear. ${ }^{48}$ Investigations in humans have found that serum ET-1 showed an exaggerated increase in both patients with primary Raynaud's phenomenon and in stoneworkers with VWF after cold challenge, as well as in VWF chain sawyers after five minute exposures to sinusoidal vibration of $120 \mathrm{~Hz}$ with an unweighted acceleration of 50 m.s. ${ }^{-2}$ rms. $^{44} 4950$ It has been reported that in isolated human arteries, threshold concentrations of ET-1 augmented the contractile responses induced by noradrenaline probably through a calcium dependent mechanism. ${ }^{51}$ Hence, the persisting vasomotor after effects found in this study might be the result of the interaction between endogenous (ET-1) and exogenous (sympathetic adrenergic nerves) vasoregulatory factors. Blood flow reduction due to an increased sympathetic response to acute vibration might be exacerbated by the release of some vasoactive substances, such as ET-1, from endothelial cells.

It is not clear whether persisting vascular after effects induced by vibration, as found in this study, lead to tissue damage in the fingers of workers after prolonged exposures to hand transmitted vibration in the workplace. It has been reported that VWF is characterised by a high vasomotor tone with no obliterative organic lesions in the finger arteries. ${ }^{52}$ Structural changes in the wall of the digital vesselssuch as subintimal fibrosis and muscular hypertrophy-have been shown only in advanced cases of VWF. ${ }^{53}$ Trophic skin changes in the fingertips have rarely been found in subjects with very severe VWF. ${ }^{54}$

International standard ISO 5349 provides methods for the assessment of vibration exposure at the workplace and for reducing vibration injuries, including $\mathrm{VWF}^{1}{ }^{1}$ The standard assumes that some characteristics of vibration (magnitude, frequency, duration) represent the principal exposure variables which account for the potential harmful effects on finger blood circulation. According to the standard, vibration acceleration should be weighted by a frequency weighting curve which has slopes of $0 \mathrm{~dB}$ below $16 \mathrm{~Hz}$ and $-6 \mathrm{~dB}$ per octave above $16 \mathrm{~Hz}$. This means that the sensitivity of the hand-arm system to acceleration is presumed to be independent of frequency below $16 \mathrm{~Hz}$ but reduces in inverse proportion to the vibration frequency at higher frequencies - that is, response is dependent on vibration velocity between 16 and $1250 \mathrm{~Hz}$. This frequency weighting has an enormous effect on the dose-response relation for VWF, information included in annex A to ISO 5349. In the annex the predicted prevalence of finger blanching is assumed to be directly proportional to the daily duration of vibration exposure, proportional to the square of the acceleration magnitude, proportional to the square of the years of exposure, and inversely proportional to the square of the vibration frequency (at frequencies above $16 \mathrm{~Hz}$ ). Thus if the vibration frequency is halved, the daily duration of exposure must be decreased by a factor of four, or the years of exposure must be 


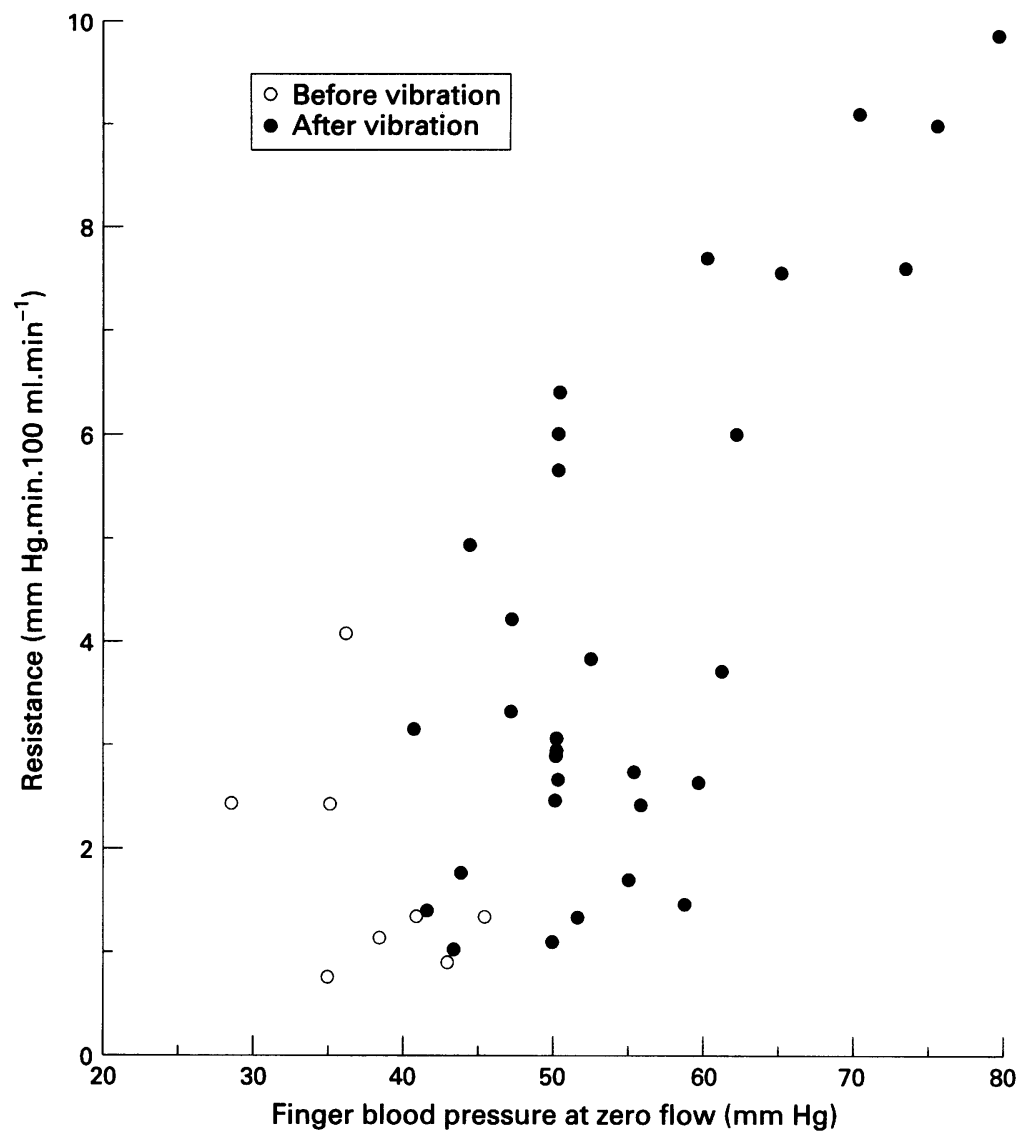

Figure 3 Scattergram of the estimates of vascular resistance $v$ finger blood pressure at zero flow in the exposed fingers of eight healthy subjects before and after 30 min exposures to vibration of $125 \mathrm{~Hz}$ and $22 \mathrm{~m} . \mathrm{s}^{-2} \mathrm{rms}$. Finger blood pressure at zero flow and vascular resistance were estimated by the intercept and the reciprocal of the slope of the pressure-flow relation at different hand heights, respectively.

decreased by a factor of two (assuming the acceleration magnitude and the predicted prevalence of VWF remain unchanged). The ISO frequency weighting curve is basically derived from an adjustment of the subjective data obtained by Miwa in the frequency range 3 to $300 \mathrm{~Hz}^{55}$ The author determined the mean equal sensation contours for vibration which gave rise to an unacceptable discomfort or unpleasantness in 10 subjects who pressed their hands on a flat horizontal surface. Thus the frequency weighting curve of ISO 5349 roughly reflects the vibration sensation in the human hand extrapolated up to the one thirdoctave band centre frequency of $1250 \mathrm{~Hz}$. It has been considered that although such sensations may be useful when assessing the neurological effects of hand transmitted vibration, they are less obviously suitable for predicting some other injuries induced by vibration such as vascular disorders. ${ }^{56}$ This subject has been discussed in several recent reports. ${ }^{57-59}$ In general, experimental studies of the pathophysiological effects of vibration on digital vasculature have had no influence on the formulation of the frequency weighting and the dose-response relation as presented in ISO 5349.56

Consideration of published data on vibration and finger blood circulation shows no firm evidence for an increase in the magnitude of vibration acceleration required to provoke digital vasoconstriction as the vibration frequency increases. ${ }^{34-10}$ Despite the sparseness of data and the differences in experimental procedures, the various studies tend to indicate that, at constant acceleration magnitudes, vibration frequencies from 30 to $500 \mathrm{~Hz}$ can consistently affect digital circulation in both healthy subjects and patients with Raynaud's phenomenon. $^{34910}$ Within this frequency range, there is some evidence that the frequency of $125 \mathrm{~Hz}$ is more effective in inducing digital vasospasm than either lower or higher frequencies. ${ }^{78}$ These findings are also supported by the results of pathological studies showing that vibration of 30,60 , and $480 \mathrm{~Hz}$ at $50 \mathrm{~m} . \mathrm{s}^{-2}$ caused comparable pathohistological changes in the peripheral arteries of experimental animals. ${ }^{60}{ }^{61}$ Therefore the use of the frequency weighting curve proposed by ISO 5349 may overestimate risk for low frequency vibration or underestimate risk for high frequency vibration. This finding is indirectly confirmed by those of the present study in which the vibration with a frequency of $125 \mathrm{~Hz}$ and a weighted acceleration of $2.8 \mathrm{~m} . \mathrm{s}^{-2}$ (unweighted acceleration of $22 \mathrm{~m} . \mathrm{s}^{-2}$ ) was found to produce an increase in the digital vasomotor tone similar to, or even greater than, that with a frequency of $31.5 \mathrm{~Hz}$ and a weighted acceleration of $11 \mathrm{~m} \cdot \mathrm{s}^{-2}$ (unweighted acceleration of $22 \mathrm{~m} \cdot \mathrm{s}^{-2}$ ). The same indication of an inconsistent correlation between frequency weighted acceleration and digital vascular response can be found if the frequency weighting factors proposed by ISO 5349 are applied to the vibration stimuli used in the studies already mentioned.

The relation between adverse circulatory effects of acute vibration and chronic vascular disorders in the finger induced by vibration is currently unknown. However, the results of this study and other experimental investigations suggest that the frequency weighting curve of ISO 5349 does not reflect the pattern of response of the digital vessels to acute vibration in either healthy subjects or patients with VWF. This conclusion seems to be supported by the findings of a recent epidemiological study of dockyard workers in which the occurrence of VWF and its severity were found to fit better with measures of vibration dose including unweighted acceleration rather than acceleration frequency weighted according to ISO $5349 .{ }^{62}$ It was considered that the standardised frequency weighting placed insufficient importance on some of the higher frequencies. The possibility that the frequency weighting does not reflect the hazard produced by vibrating tools has also been claimed in a criteria document of the National Institute for Occupational Safety and Health (NIOSH) which proposed the use of unweighted acceleration to assess vibration exposure and health risk in the United States. ${ }^{63}$

In conclusion, the results of this study indicate that acute vibration can give rise to a complex of digital circulatory responses which depend on the magnitude and frequency of the vibration stimuli. Haemodynamic measurements confirm our previous findings that vibration of $125 \mathrm{~Hz}$ and $87 \mathrm{~m} . \mathrm{s}^{-2} \mathrm{rms}$ can pro- 
duce an immediate increase in blood flow in the vibrated finger through a local mechanism. This transitory vasodilatation, probably of mechanical or biochemical origin, is followed by a vasoconstriction that can be recorded in both the vibrated and the non-vibrated finger, suggesting that a central sympathetic reflex mechanism may be operative. ${ }^{15}$ Vibration with frequencies of 31.5 and $125 \mathrm{~Hz}$ with a lower acceleration magnitude provoked an increase in vasomotor tone in either finger throughout the entire recovery period. There is experimental evidence that both extrinsic and intrinsic vasoregulatory factors could be involved in the persisting vasoconstrictor after effects induced by vibration. However, to date the relative roles of local, humoral or central sympathetic reflex mechanisms in the vasomotor changes elicited by hand transmitted vibration are still unclear. Finally, the pattern of the response of digital vessels to acute vibration with various combinations of frequencies and acceleration magnitudes does not seem to support the concept of frequency weighting assumed in ISO 5349 to characterise the sensitivity of the human hand to vibration. Further research is needed to relate the acute reactions to vibration in the laboratory to the chronic effects caused by vibration exposure at work. The results of this type of study should contribute to future standards for hand transmitted vibration as well as helping to uncover the pathophysiological mechanisms involved in the temporary and permanent changes induced by vibration.

The assistance of Ms Catherine M Ruffell in carrying out the experiment is gratefully acknowledged.

1 International Organization for Standardization. Mechanical vibration: guidelines for the measurement and the assessment of human exposure to hand-transmitted vibration. Geneva: ISO 1986:5349.

2 British Standards Institution. Measurement and evaluation of human exposure to vibration transmitted to the hand. London: human exposure to

3 Furuta M, Sakakibara H, Miyao M, Kondo T, Yamada S. Effect of vibration frequency on finger blood flow. Int Arch Occup Environ Health 1991;63:221-4.

4 Kent PJ, Williams G, Kester RC. Altered sensitivity of digital blood flow to acute vibration in patients with vasospastic disease. F Biomed Eng 1991;13:269-71.

5 Greenstein D, Kester D. Acute vibration - its effect on digital blood flow by central and local mechanisms. Proceeding of the Institute of Mechanical Engineers 1992;206:105-8.

6 McKenna KM, Blann AD, Allen JA. Vascular responses in chain saw operators. Occup Environ Med 1994;51:366-70.

7 Hyvärinen J, Pyykkö I, Sundberg S. Vibration frequencies and amplitudes in the etiology of traumatic vasospastic disease. Lancet 1973;i:791-4.

8 Welsh CL. The effect of vibration on digital blood flow. $\mathrm{Br} \mathcal{F}$ Surg 1980;67:708-10

9 Nohara S, Okamoto K, Okada A. Peripheral circulatory and nervous response to various frequencies of local vibration exposure. Scand $\mathcal{F}$ Work Environ Health 1986;12:382-4.

10 Färkillä M, Pyykkö I. Blood flow in the contralateral hand during vibration and hand grip contractions of lumberjacks. Scand $\mathcal{f}$ Work Environ Health 1979;5:368-74.

11 Sakakibara H, Iwase S, Mano T, Watanabe T, Kobayashi F, Furuta $M$, et al. Skin sympathetic activity in the tibial nerve triggered by vibration applied to the hand. Int Arch Occup Environ Health 1990;62:455-8.

12 Sakakibara $H$. Sympathetic responses to hand-arm vibration and symptoms of the foot. Nagoya fournal of Medical Science 1994;57(suppl):99-111.

13 Olsen N. Centrally and locally mediated vasomotor activities in Raynaud's phenomenon. Scand $\mathcal{F}$ Work Environ Health 1987;13:309-12.

14 Bovenzi M. Cardiovascular responses to autonomic stimulation in vibration-induced white finger. Eur $\mathcal{F}$ Appl Physio 1989;59:199-208.

15 Bovenzi M, Griffin MJ, Ruffell CM. Acute effects of vibration on digital circulatory function in healthy men. vibration on digital circulatory function
Occup Environ Med 1995;52:834-41.
16 Burton AC. Physical principles of circulatory phenomena: the physical equilibria of the heart and blood vessels. In: Hamilton WF, ed. Handbook of physiology, section 2, vol I. Washington, DC: American Physiological Society, 1962: 85-106.

17 Nichol JT, Girling F, Jerrard W, Claxton EG, Burton AC. Fundamental instability of small blood vessels and critical closing pressures in vascular beds. Am $\mathcal{F}$ Physiol 1951;164: 330-44.

18 Bellamy RF. Diastolic coronary artery pressure-flow relations in the dog. Circ Res 1978;43:92-101.

19 Sylvester JT, Gilbert RD, Traystman RJ, Permutt S. Effects of hypoxia on the closing pressure of the canine systemic of hypoxia on the closing pressure of the canial circulation. Circ Res 1981;49:980-7.

20 Ehrlich W, Baer RW, Bellamy RF, Randazzo R. Instantaneous femoral artery pressure-flow relations in supine anesthetized dogs and the effect of unilateral elevation of femoral venous pressure. Circ Res 1980;47:88-98.

21 Burton AC, Yamada S. Relation between blood pressure and flow in the human forearm. F Appl Physiol 1951;4:32939.

22 Yamada S. Effects of positive tissue pressure on blood flow in the finger. 7 Appl Physiol 1954;6:495-500.

23 Roddie IC, Shepherd JT. Evidence for critical closure of digital resistance vessels with reduced transmural pressure and passive dilatation with increased venous pressure. $f$ Physiol 1957;136:498-506.

24 Wise RA, Wigley FM, Malamet R. Digital pressure-flow relationships in subjects with Raynaud's phenomenon. Angiology 1985; 36:596-602.

25 British Standards Institution. Guide to safety aspects of experiments in which people are exposed to mechanical vibration and shock. London: BSI, 1989:7085.

26 Garrett JW. Anthropometry of the hands of male airforce flight personnel. Springfield, VA: Aerospace Medical Research Laboratory, 1970. (AMRL-TR-69-42.)

27 Nielsen PE, Bell G, Lassen NA. Strain gauge studies of distal blood pressure in normal subjects and in patients with peripheral arterial disease. Analysis of normal variation and reproducibility and comparison to intraarterial measurements. Scand $₹$ Clin Lab Invest 1973; 31(suppl 128):103-9.

28 Greenfield ADM, Whitney RJ, Mowbray JF. Methods for the investigation of peripheral blood flow. $\mathrm{Br}$ Med Bull 1963;19:101-9.

29 Greenhouse SW, Geisser S. On methods in the analysis of profile data. Psychometrika 1959;24:95-111.

30 Dewey RC, Pieper HP, Hunt WE. Experimental cerebral hemodynamics. Vasomotor tone, critical closing pressure, and vascular bed resistance. $\mathcal{F}$ Neurosurg 1974;41:597-606.

31 VanCitters RL. Occlusion of lumina in small arterioles during vasoconstriction. Circ Res 1966;18:199-204.

32 Permutt S, Riley RL. Hemodynamics of collapsible vessels with tone: the vascular waterfall. $\mathcal{F}$ Appl Physiol 1963;18: 924-32.

33 Johansson RS, Landström U, Lundström R. Responses of mechanoreceptive afferent units in the glabrous skin of the human hand to sinusoidal skin displacement. Brain Res 1982;244:17-25.

34 Ljung B, Sivertsson R. Vibration-induced inhibition of vascular smooth muscle contraction. Blood Vessels 1975;12:3852.

35 Lindblad LE, Lorenz RR, Sherpherd JT, Vanhoutte PM. Effects of vibration on a canine cutaneous artery. $A m \mathcal{F}$ Physiol 1986;250:H519-23.

36 Hudlická $\mathrm{O}$, Wright $\mathrm{A}$. The effect of vibration on blood flow in skeletal muscle in the rabbit. Clin Sci Mol Med 1978;55: 471-6.

37 Liedtke AJ, Schmid PG. Effect of vibration on total vascular resistance in the forelimb of the dog. $f$ Appl Physiol 1969;26:95-100.

38 Azuma T, Ohhashi T, Sakaguchi $\mathrm{K}$. An approach to the pathogenesis of "white finger" induced by vibratory pathogenesis of "white frimer" induced by vibratory stimulation: acute but substained changes in vascular Cardiovasc Res 1980;14:725-30.

39 Nakamura H, Nohara S, Nakamura H, Okada A. Combined effects of local vibration and noise on peripheral circulatory funcyion. In: Okada A, Manninen O, eds. Recent advances in researches on the combined effects of environmental factors. Kanazawa: Kyoe, 1987:762-81.

40 Okada A, Naito $M$, Ariizumi M, Inaba R. Experimental studies on the effects of vibration and noise on sympathetic nerve activity in skin. Eur 7 Appl Physiol 1991;62:324-31.

41 Olsen N. Vibration after effects on vasoconstrictor response to cold in the normal finger. Eur $\mathcal{f} A p p l$ Physiol to cold in the

42 Olsen N, Petring OU, Rossing N. Transitory postural vasomotor dysfunction in the finger after short term hand vibration. Br f Ind Med 1989;46:575-81.

43 Yoshida M, Nakamura H, Okazawa T, Nagase H, Okada A. Response of plasma platelet-derived growth factor (PDGF) and endothelin to vibration exposure in chain-sawyers. In Gemne G, Brammer AJ, Hagberg $M$, Lundström $R$ Nilsson T, eds. Proceedings of Stockholm Workshop 94. Handarm vibration syndrome: diagnostics and quantitative relationships to exposure. Solna: National Institute of Occupationa Health, Arbete och Hälsa 1995;5:171-8.

44 Yanagisawa $M$, Kurihara $H$, Kimura $S$, Tomobe $Y$ Kobayashi M, Mitsui Y, et al. A novel potent vasoconstrictor peptide produced by vascular endothelial cells. Nature 1988;332:411-5.

45 Haynes WG, Webb DJ. Contribution of endogenous generation of endothelin-1 to basal vascular tone. Lancet 1994;344:852-4. 
46 Clarke JG, Benjamin N, Larkin SW, Webb DJ, Davies GJ, Maseri A. Endothelin is a potent long-lasting vasoconstricMaseri A. Endothelin is a potent long-lasting vasoconstric-
tor in men. Am $¥$ Physiol 1989;257:H2033-5. (Heart Circ tor in men.

47 Nerem RM. Vibration-induced arterial shear stress. The relationship to Raynaud's phenomenon of occupational origin. Arch Environ Health 1973;26:105-10.

48 Davies PF. Flow-mediated endothelial mechanotransduction. Physiol Rev 1995; 75:519-60.

49 Zamora MR, O'Brien RF, Rutherford RB, Weil JV. Serum endothelin-1 concentrations and cold provocation in primary Raynaud's phenomenon. Lancet 1990;336:1144 7.

50 Palmer KT, Mason H. Serum endothelin concentrations in workers exposed to vibration. Occup Environ Med 1996;53: 118-24.

51 Yang Z, Richard V, von Segesser L, Bauer E, Stulz P, Turina $M$, et al. Threshold concentrations of endothelin-1 potentiate contractions to norepinephrine and serotonin in human arteries. A new mechanism of vasospasm? Circulation 1990; 82:188-95.

52 Ekenvall L, Lindblad E, Bevegård S, Etzell BM. High vascular tone but no obliterative lesions in vibration white fingers. Am ₹ Ind Med 1987;12:47-54.

53 Ashe WF, Williams N. Occupational Raynaud's II: further studies of this disorder in uranium mine workers. Arch Environ Health 1964;9:425-33.

54 Walton KW. The pathology of Raynaud's phenomenon of occupational origin. In: Taylor $\mathrm{W}$, ed. The vibration symdrome. London: Academic Press, 1974:109-19.

55 Miwa T. Evaluation methods for vibration effect. Part 3 Measurements of thresholds and equal sensation contours on hand for vertical and horizontal sinusoidal vibrations. Ind Health 1967;5:213-20.

56 Griffin MJ. Foundations of hand-transmitted vibration standards. Nagoya fournal of Medical Science 1994 57(suppl):147-64.

57 Gemne G, Lundström R, Hansson JE. Disorders induced by work with hand-held vibrating tools. Solna: National Institute of Occupational Health, Arbete och Hälsa, 1993:6.

58 Griffin MJ. Hand-transmitted vibration and its effects: a coherence between science and standards? In: Gemne G, Brammer AJ, Hagberg M, Lundström R, Nilsson T, eds Proceedings of Stockholm Workshop 94. Hand-arm vibration syndrome: diagnostics and quantitative relationships to exposure. Solna: National Institute of Occupational Health Arbete och Hälsa 1995;5:47-58.

59 Gemne G, Lundström R. ISO 5349: validity of frequency weighting and model for white finger risk prediction. In: Gemne G, Brammer AJ, Hagberg $M$, Lundström $R$ Nilsson T, eds. Proceedings of Stockholm Workshop 94. Handarm vibration syndrome: diagnostics and quantitative relationarm vibration syndrome: diagnostics and quantitative relationHealth, Arbete och Hälsa 1995;5:33-45.

60 Okada A, Inaba R, Furuno T. Occurrence of intimal thickening of the peripheral arteries in response to local vibration. $B r \mathcal{F}$ Ind Med 1987;44:470-5.

61 Inaba R, Furuno T, Okada A. Effects of low- and high-frequency local vibration on the occurrence of intima thickening of the peripheral arteries of rats. Scand $¥$ Work Environ Health 1988;14:312-6.

62 Nelson C, Griffin MJ. Comparison of predictive models for vibration-induced white finger. In: Dupuis $\mathrm{H}$, Christ E, Sandover DJ, Taylor W, Okada A, eds. Proceedings of the 6th International Conference on Hand-Arm Vibration. Bonn: International Conference

63 National Institute for Occupational Safety and Health. Criteria for a recommended standard: occupational exposure to hand-arm vibration. Cincinnati: US Department of Health and Human Services, National Institute for Occupational Safety and Health, DHHS (NIOSH), 1989. (Publ No 89-106.)

\section{Correspondence and editorials}

Occupational and Environmental Medicine welcomes correspondence relating to any of the material appearing in the journal. Results from preliminary or small scale studies may also be published in the correspondence column if this seems appropriate. Letters should be not more than 500 words in length and contain a minimum of references. Tables and figures should be kept to an absolute minimum. Letters are accepted on the understanding that they be subject to editorial revision and shortening.

The journal also publishes editorials which are normally specially commissioned. The Editor welcomes suggestions regarding suitable topics; those wishing to submit an editorial, however, should do so only after discussion with the Editor. 